\title{
O LABORATÓRIO NACIONAL DE LUZ SÍNCROTRON
}

José Antônio Brum

Rogério Meneghini

Resumo: Neste artigo será mostrado o processo de construção do Laboratório Nacional de Luz Síncrotron (LNLS). Será discutida a estratégia e filosofia de sua implantação, procurando delinear o caminho seguido na instalação do primeiro laboratório nacional aberto à comunidade. Finalmente, discutir-se-á os desafios da segunda fase do LNLS, quando ele se consolida como instituição de pesquisa de classe mundial.

Palavras-chave: síncrotron; nanotecnologia; biotecnologia.

Abstract: This article describes the process leading up to the establishment of the Brazilian Sychrotron Light National Laboratory (LNLS), the first national laboratory open to the public. Special attention is given to the strategy and philosophy guiding the various phases of its implementation. Furthermore, the author will address the challenges facing the second phase of the LNLS, in which the Laboratório begins to consolidate its role as a world-class research institute.

Key words: synchroton; nanotechnology; biotechnology.

$\mathrm{O}$ s primeiros debates sobre a construção de uma fonte de luz síncrotron no Brasil ocorreram em 1981. Inicialmente proposto para ser construído como parte do Centro Brasileiro de Pesquisas Físicas (CBPF), o anel síncrotron tinha como objetivos a formação de mão-deobra qualificada em ciência e tecnologia no Brasil e o aumento do número de pesquisadores em física experimental. A decisão sobre a construção do anel síncrotron só aconteceu em 1984, quando foi criado o Laboratório Nacional de Radiação Síncrotron (nome alterado posteriormente). A escassez de recursos financeiros culminou, no entanto, com o adiamento de sua instalação. Em 1985, afinal, decidiu-se financiar uma pequena equipe de engenheiros e físicos que foram enviados ao Stanford Synchrotron Radiation Laboratory (SSRL). Lá, em colaboração com o Prof. H. Wiedemann, prepararam o primeiro projeto conceitual para um anel que operaria na energia de $2 \mathrm{GeV}$. Este projeto serviu de base para as discussões que levaram o Ministério de Ciência e Tecnologia (MCT) e o Centro Nacional de Desenvolvimento Científico e Tecnológico $(\mathrm{CNPq})$ à decisão, em 1986, de criar o Laboratório Nacional de Luz Síncrotron (LNLS), nome que passou a vigorar até o presente. Deu-se início à construção em janeiro de 1987.

\section{PRIMEIRA FASE: CONSTRUÇÃO E INSTALAÇÃO DO LABORATÓRIO}

A cidade de Campinas, no Estado de São Paulo, foi escolhida para sediar o LNLS. A cidade é sede da Universidade Estadual de Campinas (Unicamp), um dos principais centros de pesquisa do país. Possuindo várias indústrias, a cidade constitui-se hoje no segundo maior centro de pesquisa tecnológica do Brasil (Piza, 2001).

Desde o início dos debates sobre a construção de um anel síncrotron tinha-se como objetivo desenvolver um grande equipamento que permitisse promover a pesquisa experimental no Brasil em um conceito de laboratório nacional, aberto e multidisciplinar. O projeto conceitual do LNLS pode ser resumido em uma estratégia que envolve três idéias básicas (Silva et alii, 1988; Tavares), propostas nos primeiros anos do projeto e válidas ainda hoje:

- um grande projeto de engenharia, desafiador, que permitisse atrair uma massa crítica de jovens pesquisadores e engenheiros que seriam treinados nas tecnologias-chave, acelerando o desenvolvimento desses campos no país; - a construção de uma instalação experimental que oferecesse condições no estado-da-arte para grande número 
de pesquisadores, de diferentes áreas, em pesquisa básica e aplicada;

- a introdução do conceito de laboratório nacional, com acesso aberto às instalações a serem utilizadas - sobretudo por pesquisadores de outras instituições -, com equipe reduzida de pesquisadores da casa produzindo resultados científicos de alta qualidade, mantendo, assim, as instalações atualizadas.

Dessas idéias básicas, pode-se extrair um tripé conceitual que guiará o desenvolvimento do laboratório (Silva, 1996): organização - engenharia-ciência.

No item Engenharia, desde o início do projeto, ficou estabelecida a decisão de se desenvolver o conhecimento sobre a construção de aceleradores, produzindo, sempre que possível, os componentes e equipamentos da máquina no Brasil. Essa opção propiciou dominar o ciclo completo do desenvolvimento, construção e operação de aceleradores de partículas. A mesma opção foi feita em relação às linhas de luz - as estações experimentais que utilizam a luz síncrotron - acopladas ao anel. Essa estratégia permitiu, além de reduzir o custo da máquina, adquirir o conhecimento necessário para manutenção e sua posterior atualização, e oferecer alta capacidade de instrumentação experimental.

No aspecto Ciência, buscou-se construir uma fonte de luz síncrotron que desse acesso a uma ampla comunidade científica usufruir das instalações. De fato, o LNLS dispõe de instalações experimentais que permitem estudar a composição dos materiais até o nível atômico, essencial para a ciência e engenharia de materiais, propriedades de superfície e propriedades químicas de materiais, além de aplicações em ciências do meio ambiente e geociências. Embora não fosse uma das aplicações previstas no início do projeto, o rápido desenvolvimento da cristalografia de proteínas que utiliza fonte de luz síncrotron como fonte de raios $\mathrm{X}$ de grande intensidade e a importância estratégica dessa pesquisa na área farmacêutica além da pesquisa básica, aumentaram enormemente a demanda de fonte de luz síncrotron para aplicações biológicas. Essa multidisciplinaridade, inerente a esse tipo de laboratório, é uma das características do LNLS e oferece ambiente propício ao intercâmbio entre pesquisadores de diversas áreas.

Finalmente, no item Organização introduziu-se o conceito de laboratório nacional, aberto, e seus equipamentos compartilhados pelos pesquisadores de outras instituições de pesquisa, acadêmicas e industriais. Esse conceito era novo no país, em que se praticava a cultura de pesquisa compartimentalizada, em laboratórios peque-

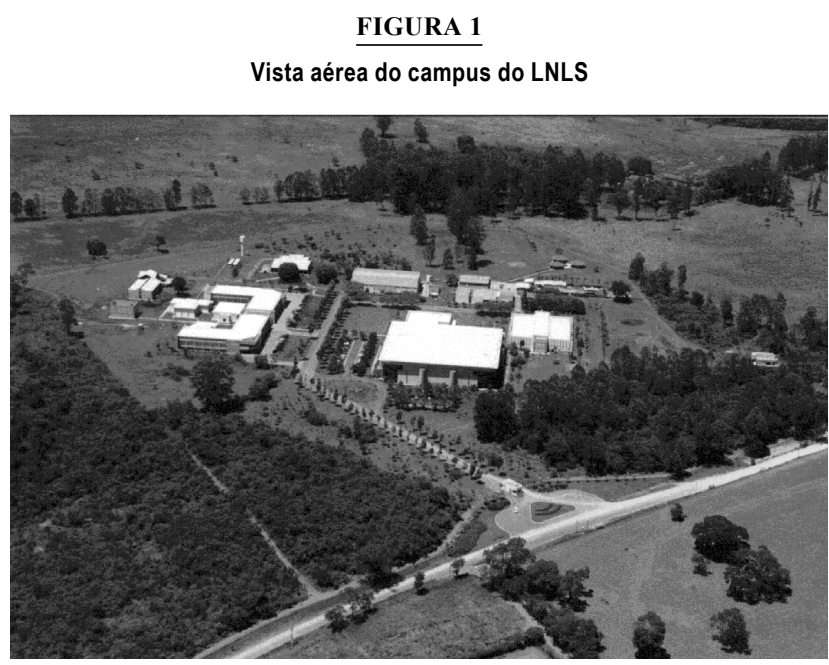

nos, com pouca interação. A decisão estratégica de construir-se o laboratório síncrotron desenvolvendo a tecnologia no Brasil, admitiu ao LNLS desempenhar papel importante na promoção de interação entre o setor científico e tecnológico no país. O LNLS desenvolve forte colaboração internacional, e mantém intercâmbio regular de pesquisadores, engenheiros e técnicos. Ele exercerá um papel importante como pólo científico no Brasil e na América Latina. Por fim, mais recentemente, o LNLS foi pioneiro na forma de organizar a gestão da ciência por meio de uma nova forma institucional, a Organização Social.

\section{Construção da Fonte de Luz Síncrotron}

A equipe que construiria o LNLS começou a ser formada em 1986. Ela foi liderada pelo diretor do LNLS, Cylon Gonçalves da Silva, pelo diretor técnico, A. Ricardo Rodrigues, responsável pelo projeto de engenharia da máquina, e pelo diretor científico, Aldo Craievich, responsável pela mobilização da comunidade científica e formação dos primeiros usuários.

Havia, na época, pouca experiência na física e engenharia de aceleradores. Foi necessário adotar uma estratégia para a formação técnica da equipe (Silva, 1996) com base na competência e experiência dos selecionados. Procedeu-se a um treinamento na casa conforme seminários, cursos e trabalhos práticos. Essa opção, oposta a de enviar membros da equipe ao exterior para o treinamento, possibilitou adquirir-se a experiência e aplicá-la de imediato no próprio ambiente de trabalho. Além disso, parte do pessoal técnico tinha sido enviada a laboratórios simi- 
lares no mundo, por um curto período, para atacar problemas específicos. Foram trazidos consultores do exterior para revisar o andamento do projeto. Essa sistemática possibilitou formar uma equipe jovem, coesa e entusiástica, permitindo trabalhar com a flexibilidade necessária para fazer as escolhas adequadas ao contexto e restrições orçamentárias. Ademais, o processo de formação dessa equipe contribui de maneira significativa para o desenvolvimento de uma cultura de laboratório nacional no LNLS.

A primeira metade de 1987 foi dedicada a procurar um local temporário para o laboratório, contratando o pessoal técnico, planejando as instalações e adquirindo o equipamento básico. Com a equipe técnica e administrativa ocupando as instalações provisórias, já em 1987 a equipe começa o desenvolvimento dos equipamentos. O projeto inicial (que será chamado de Projeto 1), preparado em 1985, consistia em um anel de armazenamento de elétrons de alto brilho de 2-3 GeV, com energia total de injeção. A injeção seria feita por um acelerador linear (Linac) de 100-200 MeV seguido de um síncrotron injetor. A construção do anel de armazenamento requeria um alto nível de conhecimento técnico. Uma tarefa mais acessível foi a construção do Linac, que servirá como etapa de formação e treinamento para a equipe, preparando-a para a construção de todo o laboratório. Devido às limitações de espaço nos locais temporários, optou-se por construir um Linac menor, de $50 \mathrm{MeV}$, deixando para a construção completa do Linac uma vez instalados no local definitivo. Essa etapa levou dois anos e meio e em 22 de dezembro de 1989 o feixe foi observado pela primeira vez no Linac.

Em 1989 o projeto original é revisado. Desde o princípio, sabia-se que antes de iniciar a construção do anel essa revisão seria necessária, procurando ajustar-se às evoluções tecnológicas das máquinas síncrotrons. O Projeto 1 possuía poucas seções retas, onde são instalados os dispositivos de inserção (onduladores e wigglers), os quais permitem obter alta intensidade de fluxo ou raios $\mathrm{X}$ duros (mais energéticos). A tecnologia desses dispositivos só vai aperfeiçoar-se ao longo dos anos 80. De mais a mais, as dificuldades econômicas encontradas, em particular com a crise no início de 1989, forçam uma adequação do orçamento e, com isso, do tamanho do anel projetado. O novo projeto do anel de armazenamento obedeceu às seguintes orientações (Silva, 1989): a) manter o cronograma original, isto é, ser comissionado em 1992; b) ser uma fonte de luz cientificamente interessante; c) técnica e financeiramente no alcance da equipe do LNLS; d) a equipe do LNLS deveria assumir total responsabilidade do projeto e da construção; e e) não deveria prejudicar o objetivo final estabelecido nas linhas do Projeto 1 . O novo projeto, UVX2, é dedicado à região espectral de Ultravioleta (UV) e de raios $\mathrm{X}$ moles (menos energéticos), constituído de um anel de armazenamento de $1,15 \mathrm{GeV}$, com uma corrente de 100 $\mathrm{mA}$, e injetado por um Linac de $120 \mathrm{MeV}$. Teria poucos elementos e algumas seções retas, prevendo a instalação dos dispositivos de inserção, quando poderia então produzir feixe de luz intenso na faixa espectral dos raios $\mathrm{X}$ duros. O novo anel deve tolerar a injeção à baixa energia, diretamente no Linac, passando a ter dupla função de anel acelerador e armazenador. É importante salientar que a injeção de elétrons no anel com energia bem abaixo da de armazenamento é uma operação pouco usual em anéis síncrotrons. O sucesso desse procedimento demonstrou a capacidade da equipe técnica, de acordo com a estratégia utilizada para sua formação.

A instabilidade econômica e política do país no período 1991-1993 exigiu razoável esforço da equipe, que continuou seus trabalhos, desenvolvendo protótipos de vários componentes do anel de armazenamento e instrumentação científica. Em 1992, é construída a primeira linha de luz, na região de UV, que foi instalada no Center for Advanced Microstructures and Devices (CAMD) of Louisiana State University, em Baton Rouge (EUA). Ela propicia também aos pesquisadores e técnicos adquirir experiência na instalação, comissionamento e funcionamento de linhas de luz.

Em 1993, o financiamento do laboratório retoma seu curso normal, tornando possível o desenvolvimento e a construção do LNLS no ritmo desejado. Em outubro de 1995, a equipe começa a transferir-se para a sede definitiva, numa área de 38 hectares na região do II Pólo de Alta Tecnologia de Campinas, próxima à Unicamp, que fora cedida em 1990, pelo Estado de São Paulo. Iniciouse a montagem da fonte de luz síncrotron. Nesse tempo, a equipe projeta e constrói vários dos subsistemas da máquina (Tavares). O injetor Linac de $120 \mathrm{MeV}$ é montado no túnel iniciando sua operação, na energia nominal, em 22 de dezembro de 1995. Em 22 de maio de 1996 a primeira volta dos elétrons no anel de armazenamento foi observada e em 30 de maio obteve-se o primeiro feixe armazenado. Finalmente, em maio de 1997 a corrente acumulada atingiu $120 \mathrm{~mA}$ (acima dos $100 \mathrm{~mA}$ projetados). A alta qualidade dos magnetos permitiu que a energia normal de operação atingisse $1,37 \mathrm{GeV}$. A superação desses parâmetros, corrente de injeção e energia final, além do tempo de vida da corrente, possibilitou oferecer linhas 
de luz eficientes na região de raios $\mathrm{X}$ duros, mesmo antes da instalação de dispositivos de inserção.

No segundo semestre de 1996 as primeiras linhas de luz foram instaladas, admitindo que, já no início de seu funcionamento, o LNLS tivesse 7 linhas de luz construídas ou em construção (de um total possível de 24): absorção de estrutura fina de raios X (XAS), espectroscopia de raios $\mathrm{X}$ moles (SXS), espalhamento de baixo ângulo (SAS), difração de raios X (XRD), cristalografia de proteínas (PCR) e duas linhas de espectroscopia UV, uma com monocromador de grade esferoidal (SGM) e a outra com monocromador de grade toroidal (TGM). Finalmente, o LNLS é inaugurado em julho de 1997, começando sua operação rotineira para os usuários.

Em paralelo com a construção do laboratório, o LNLS desenvolveu um ativo trabalho de preparação da comunidade científica, organizando cursos e oficinas que envolviam técnicas e aplicações de luz síncrotron. As Reuniões Anuais de Usuários (RAU) já foram iniciadas em 1990. Essas reuniões adquirem grande importância, permitindo a divulgação de trabalhos científicos que utilizam a luz síncrotron de outros laboratórios no mundo e ampla discussão das técnicas e procedimentos a serem desenvolvidos no LNLS. Como conseqüência desse esforço, já no início de sua operação, o LNLS possuía um número significativo de usuários. Esses eventos continuam sendo hoje uma atividade de grande importância para o LNLS.
Nos anos que se seguirão, novas linhas de luz são construídas. Em 1998, a linha de luz de fluorescência (XRF) e de instrumentação (XRI) são comissionadas. Atendendo a demanda dos usuários, em 1999 a linha de instrumentação é adaptada em uma nova linha de difração (XD2), e uma linha dedicada à litografia de raios X e UV (XRL) é construída, totalizando 10 linhas de luz.

Em julho de 1998, a Divisão de Aceleradores do LNLS começa o trabalho de melhorias no sistema de injeção do anel. Um síncrotron injetor é projetado e será instalado entre o Linac e o anel de armazenamento. Ele permitirá uma injeção mais eficiente, em uma energia intermediária de $500 \mathrm{MeV}$, levando a atingir correntes maiores e uma diminuição das dimensões verticais do feixe, possibilitando a instalação dos dispositivos de inserção. A construção levou dois anos e meio e em novembro de 2000 o síncrotron injetor foi comissionado. Finalmente em julho de 2001 o síncrotron começa a operar com o novo sistema de injeção. Embora já tenha atingido correntes na injeção de $300 \mathrm{~mA}$, o anel síncrotron opera, hoje, com uma corrente de $200 \mathrm{~mA}$ e com uma energia de 1,37 $\mathrm{GeV}$. A operação em correntes maiores será possível após melhorias no anel, previstas para 2002.

\section{Nova Forma de Gestão: Organização Social}

Do ponto de vista administrativo, desde o início percebeu-se que a singularidade institucional de um laboratório

\section{GRÁFICO 1}

Projetos Realizados no Laboratório Nacional de Luz Síncroton

Brasil - 1997 - 2001

Fonte de Luz Síncrotron $\square$ Laboratório de Microscopia Eletrônica

Número de projetos

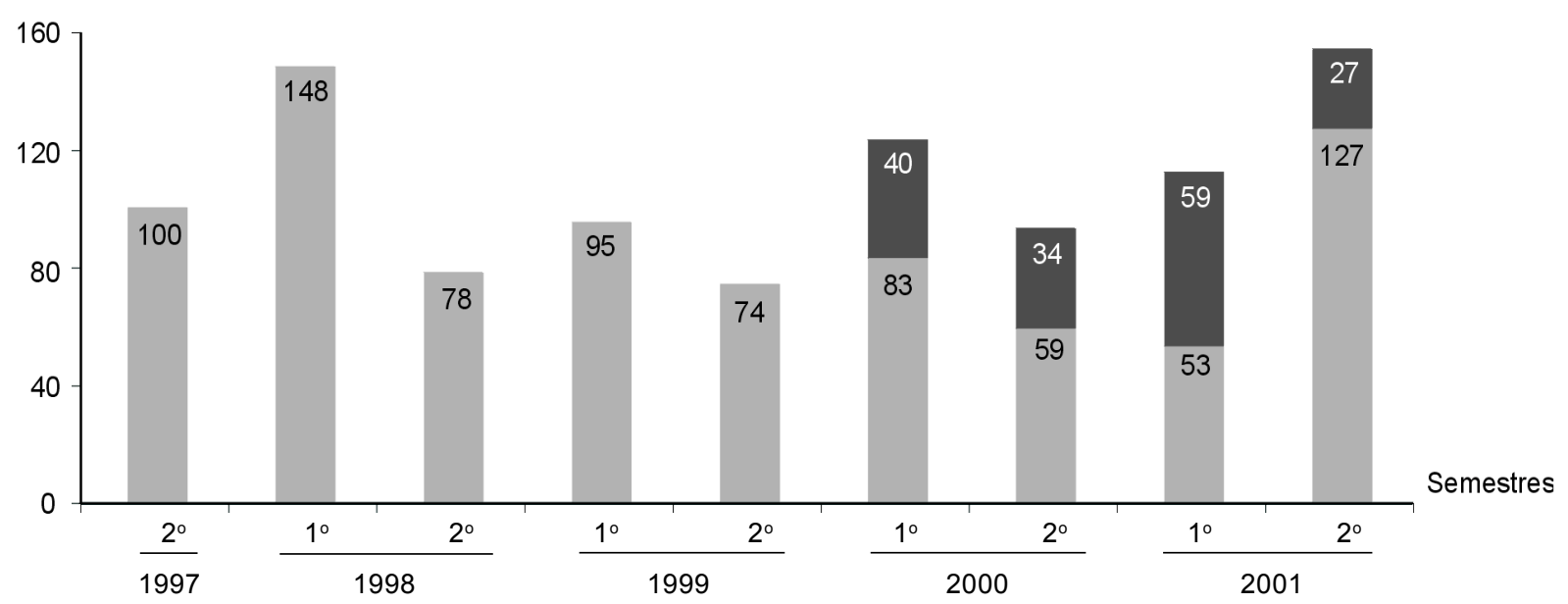




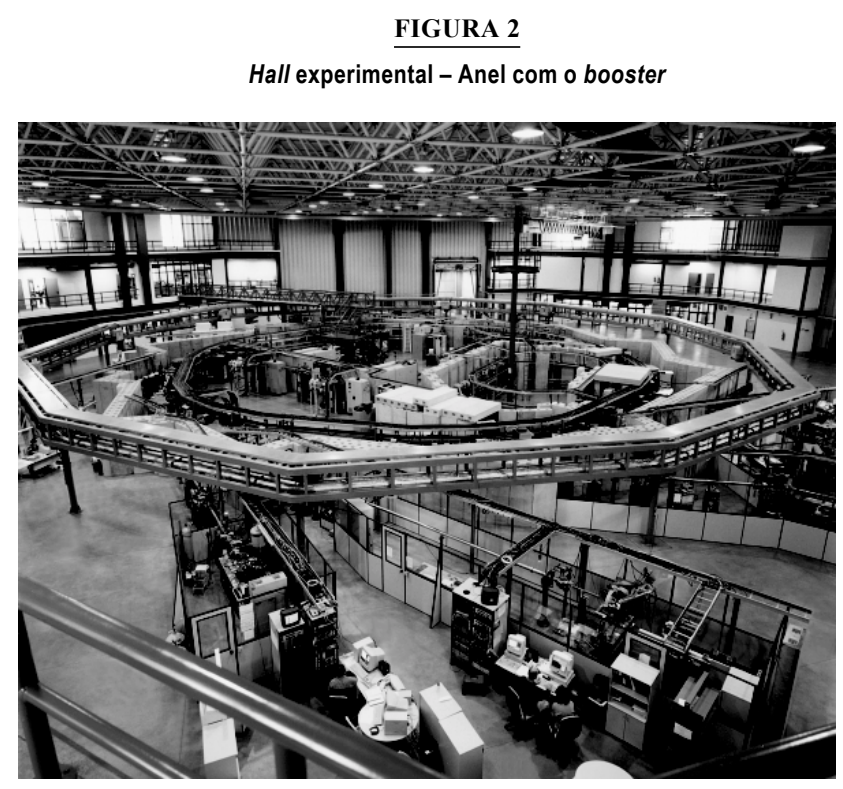

nacional necessitava de um modelo de gestão mais ágil e dinâmico que a tradicional administração pública permitia.

Já em 1993 começa a discussão sobre essa nova forma de gestão e alcança um impulso importante com o novo governo em 1995. Esse novo modelo adquire forma com a criação das Organizações Sociais (OS). Estas são entidades de direito privado, sem fins lucrativos, com objetivos de diversas naturezas. Elas poderão celebrar Contratos de Gestão (CG) com o Poder Executivo, com vista na formação de parceria para realizar o fomento e execução das atividades previstas. Dentro desse novo modelo, e visando a gestão do LNLS, é criada em 13 de outubro de 1996 a Associação Brasileira de Tecnologia de Luz Síncrotron (ABTLuS), qualificada como OS. O CG entre a ABTLuS e o CNPq e o MCT foi assinado em 29 de janeiro de 1998, passando então a ABTLuS a operar o LNLS para o CNPq/MCT.

Por intermédio do CG, a ABTLuS propõe um Plano de Trabalho para o LNLS no qual são delineadas as grandes linhas da proposta de trabalho na vigência do CG. Foram estabelecidas metas para o desenvolvimento desse Plano e definidos Indicadores para o seu cumprimento. Dessa forma, a ABTLuS assume uma responsabilidade clara em relação a seus objetivos no CG, procurando maior eficiência, eficácia e economicidade na gestão do bem público. A nova forma de gestão é avaliada anualmente, com acompanhamento semestral, por um Comitê de Avaliação do $\mathrm{CNPq} / \mathrm{MCT}$. Um Comitê Científico, composto por pesquisadores nacionais e estrangeiros de renome, reúnese bienalmente para acompanhar, avaliar e fazer suges- tões quanto ao plano mais geral nos aspectos científicos do laboratório. O sucesso desse novo tipo de administração permitirá que, ao longo dos próximos anos, esse novo modelo de gestão pública, não estatal, possa consolidar-se.

\section{SEGUNDA FASE: UMA INSTITUIÇÃO DE PESQUISA DE CLASSE MUNDIAL}

Com a conclusão do anel e início das operações depara-se com um novo desafio, que é o da consolidação do LNLS como instituição de pesquisa de classe mundial. Esse novo desafio pode ser visto não apenas como prosseguimento natural do laboratório, mas como exigência da sociedade para com o LNLS. Várias são as razões de prosseguir nessa direção:

- o aspecto multidisciplinar no laboratório que propicia um ambiente favorável a interdisciplinaridade, característica cada vez mais importante na pesquisa;

- a característica de laboratório aberto, multiusuário, que se mostra uma opção interessante para otimizar os recursos aplicados em ciência e tecnologia;

- a capacidade para o desenvolvimento de instrumentação científica, necessária para o trabalho de pesquisa e a ampliação da capacidade experimental dos usuários;

- a necessidade que o país tem de utilizar ao máximo seus recursos materiais e humanos no desenvolvimento científico e tecnológico;

- a possibilidade de atuar, junto ao MCT, na tarefa de promover a pesquisa científica, tecnológica e inovadora no país.

Estas razões delineiam os rumos no qual o LNLS desenvolve-se nessa sua segunda fase de existência. Duas áreas de pesquisa mostram-se particularmente apropriadas para a expansão do LNLS: nanoestruturas e biologia estrutural.

\section{Programa de Micro e Nanotecnologia}

A fonte de luz síncrotron do LNLS propicia excelentes ferramentas de análise de objetos de dimensões pequenas, até da ordem do átomo. Atualmente, a tecnologia na região do micrômetro já é bem dominada. Dá-se agora forte ênfase às investigações dos fenômenos em objetos de dimensões nanométricas (Scientific American, 2001). A construção e a manipulação desses objetos, além do estudo científico básico, visam às aplicações tecnológicas, e é uma das áreas de importância estratégica no Brasil e no Mundo (Roco, 1999). O LNLS realiza um esforço cientí- 
fico nessa área, com um pequeno grupo de pesquisadores em nanoestruturas.

Como conseqüência desse esforço, em 1998, iniciouse a instalação do Laboratório de Microscopia Eletrônica (LME), parcialmente financiado pela Fundação de Amparo à Pesquisa do Estado de São Paulo (Fapesp). O LME possui três microscópios e uma completa sala de preparação de amostras. O principal equipamento é um microscópio de transmissão eletrônica de alta resolução (HRTEM) de $300 \mathrm{kV}$ que permite uma resolução de até $1,7 \AA$. Além deste, encontram-se também um microscópio eletrônico de varredura de emissão por campo e um de baixo vácuo. Seguindo a filosofia do LNLS, esse laboratório opera em instalação aberta aos usuários. Constata-se o sucesso da estratégia implantada pelo número de usuários que utiliza o laboratório (Gráfico 1).

Em 1999 começou a ser implantado o Laboratório de Microscopia e Força Atômica, com dois microscópios, um de força atômica e outro de tunelamento à ultra alto vácuo. Estes microscópios vão aumentar a capacidade de análise de micro e nanoobjetos, possuindo resolução atômica.

Em torno de uma linha de luz dedicada à litografia de raios $\mathrm{X}$ e UV, foi desenvolvido um laboratório de microfabricação. O equipamento disponível admite uma resolução de alguns micrômetros. Os trabalhos são organizados em torno do Projeto Multiusuário de Microfabricação (Musa), autorizando pesquisadores das áreas de engenharia, física, química e biologia ao acesso a processos de microfabricação, propiciando a capacitação nacional em projetos de microssistemas.

Por intermédio de sua equipe de pesquisadores, o LNLS procura desenvolver suas atividades também como integrante no fomento à pesquisa com a participação na Rede de Nanoestruturas, do CNPq, formada e aprovada em 2001.

\section{Centro de Biologia Molecular e Estrutural}

Os esforços de seqüenciamento de genomas estão produzindo dramático impacto em biologia, ciências médicas e agrárias. Vinte e cinco anos atrás não se poderia imaginar que a seqüência de milhares de bases do DNA de um gene poderia ser determinada. Em 1977 Frederick Sanger (um dos poucos ganhadores de dois prêmios Nobel) desenvolveu um método de seqüenciamento de DNA que foi aperfeiçoado ao longo dos anos. Agora vários genomas, com milhares de genes, são seqüenciados - até mesmo o genoma humano que possui dezenas de milhares de genes. Essa seqüência está completa, bem como a de outros genomas de várias outras espécies, e como conseqüência os pesquisadores estão voltando suas atenções para os aspectos funcionais dele. Um dos componentes mais importantes dessa nova fase é o estudo de estrutura de proteínas expressas por esses genes. Um esforço sistemático para elucidar, em elevado fluxo, estruturas de proteínas com base em genes de diferentes genomas está sendo feito nos Estados Unidos, Europa e Japão. Esses programas têm sido chamados de genomas estruturais. A estrutura e a função de uma proteína são intimamente correlacionadas. A elucidação de mais de 14 mil estruturas de proteínas, depositadas no Protein Data Base até o momento, torna possível prever funções valendo-se dessas estruturas. Daí a grande importância desses estudos.

Essa área está-se tornando importante também do ponto de vista médico e econômico. Proteínas envolvidas em processos patológicos podem ter suas estruturas elucidadas. Com essas estruturas podem-se desenhar substâncias que se ligam especificamente às proteínas, inibindo-as. Tais inibidores podem resultar em medicamentos e são já vários os casos bem-sucedidos desse procedimento, o qual passou a ser chamado de desenho racional de drogas.

A Biologia Molecular Estrutural tem crescido de forma exponencial nos últimos anos. Além das razões já expostas, progressos tecnológicos tiveram grande impacto, como:

- crescente número de anéis de luz síncrotron que fornecem linhas de luz com alta densidade de fótons de Raios $\mathrm{X}$ duros, situação muito favorável para a cristalografia de proteínas;

- advento de equipamentos de ressonância nuclear magnética de alta freqüência (500-800 MHertz);

- desenvolvimento de hardware e software cada vez mais poderosos.

Para se ter uma idéia desse crescimento em 1990, 1995 e 2000, os números cumulativos de estruturas de proteínas depositadas na Base de Dados de Proteínas (PDB) foram, respectivamente, 600,4000 e 14.200. O Brasil contribui de maneira ainda pouco significativa nessa área. Não mais do que 40 estruturas foram elucidadas no país, o que significa em torno de $0,3 \%$ do total. Esse dado pode ser comparado com a contribuição atual do Brasil em todas as áreas de ciência que gira em torno de 1,2\% e mostra que o país necessita desenvolver estratégias para evoluir em biologia estrutural. Esforço considerável vem sendo realizado com esse objetivo no LNLS, onde, em 1998, começou a implantação do Centro de Biologia Molecular 
Estrutural (CBME), onde hoje existem em pleno funcionamento laboratórios que realizam todas as etapas de elucidação de estruturas protéicas.

Desde 2001, o CBME coordena uma Rede de Biologia Molecular Estrutural do Estado de São Paulo (SMOLBNet), integrada atualmente por 16 grupos científicos, com recursos da Fapesp. Em proposta semelhante e que agora se amplia - mediante apoio do Ministério da Ciência e Tecnologia (MCT) -, é a instalação de uma rede em nível nacional, com 10 outros laboratórios, totalizando 26 laboratórios que trabalham em rede, cada um desenvolvendo esforços para elucidar a estrutura de cerca de 5-10 proteínas, ou seja, cerca de 200 proteínas no total. Admitindo uma taxa de sucesso de $30 \%$ - que é um número realista nessa área, uma vez que em cada etapa do processo há gargalos que, algumas vezes, não podem ser superados -, serão, em quatro anos, estabelecidas as estruturas de cerca de 60 proteínas, número superior ao que até esse momento foi alcançado no Brasil.

Muitas dessas proteínas são investigadas com propósitos de se alcançar uma forma de combater uma doença, seja de humanos, animais ou plantas. De fato, mais do que $50 \%$ dos remédios nas prateleiras de farmácias atuam sobre uma proteína que está envolvida em alguma etapa metabólica de um organismo, inibindo-a ou estimulando-a. Como já discutido, medicamentos podem agora ter sua estrutura modelada com base no conhecimento da estrutura da proteína que será seu alvo.

Entre as proteínas que serão investigadas nessa rede, há algumas que foram escolhidas com base no possível papel que desempenham em doenças, de acordo com a decifração de genomas que codificam proteínas patogênicas. O Projeto Onsa da Fapesp completou ou está em vias de completar o seqüenciamento de vários genomas envolvidos em doenças de plantas, como o de bactérias fitopatogênicas, cujos genomas foram seqüenciados. Entre eles está o genoma de Xylella fastidiosa que causa uma doença chamada Citrus Variegated Chlorosis (CVC), popularmente conhecida como amarelinho, que tem causado grandes prejuízos à lavoura de laranja; outros genomas, os de três variedades de Xanthomonas, estão em fase de término de seqüenciamento, um deles especialmente importante, o de Xanthomonas citri, responsável por outra doença da lavoura cítrica, o cancro cítrico, que também traz grandes prejuízos aos agricultores. Vários genes dos genomas desses dois tipos de bactérias estão merecendo atenção especial, pois poderão estar produzindo proteínas envolvidas no processo patogênico.
Outro projeto de seqüenciamento extremamente importante no programa Onsa é o Genoma Câncer no qual são seqüenciados genes ativos (isto é, que geram proteínas, sobretudo em células mais complexas como as humanas, pois apenas parte dos genes está, em certo momento, ativa) em células de tumores de alta incidência no Brasil. A comparação de genes ativos nesses tumores com a de genes ativos em células normais poderá inferir, em nível molecular, quais proteínas estarão envolvidas no processo carcinogênico. Elas poderão ter suas estruturas tridimensionais (3D) determinadas para concluir suas possíveis funções.

Nacionalmente, uma rede nos mesmos moldes foi formada com recursos do Ministério de Ciência e Tecnologia e já teve sucesso. Foi possível decifrar a seqüência do genoma da bactéria Chromobacterium violaceum. O processo de anotação, isto é, determinação de quais são as regiões que compõem cada gene, está em desenvolvimento e deverá terminar em poucos meses. A Chromobacterium violaceum é uma bactéria de grande potencial biotecnológico: além de sintetizar compostos antibióticos e antitumorais, pode levar ao desenvolvimento de bioplásticos e reduzir impactos em áreas de garimpo. O seqüenciamento do genoma da Chromobacterium violaceum viabiliza estudos sobre as proteínas produzidas pela bactéria que podem dar origem a novos compostos, produtos e serviços.

Nas Redes de Biologia Molecular Estrutural, tão importante quanto elucidar novas estruturas 3D de proteínas serão os recursos humanos formados. De fato, em razão da importância da área e do reduzido número de pesquisadores brasileiros nela inseridos, ficou evidente que um esforço, em nível nacional, deveria ser feito para a formação de pesquisadores qualificados que dominassem as metodologias necessárias para determinação de estruturas 3D. A formação das redes de biologia estrutural já mencionadas visa também alcançar essa meta.

O sucesso de trabalho científico em redes tem sido demonstrado nos últimos anos. Redes são úteis quando o trabalho a ser executado é de grande porte. Entretanto, também o compartilhamento do domínio das distintas etapas do processo, a troca de informações, as discussões periódicas, induzem um trabalho articulado e rico, que a soma dos trabalhos dos laboratórios, individualmente, não conseguiria alcançar. Nacionalmente, isso foi demonstrado pelo sucesso dos projetos genomas. Essa sistemática está sendo implantada internacionalmente em pesquisas de naturezas diversas. Ao mesmo tempo que se reduz o caráter competitivo quando se tem laboratórios trabalhando 
individualmente, ganha-se em rapidez e economia para alcançar metas. O fator estímulo é gerado pela co-participação de diferentes grupos na busca de soluções de problemas no campo de rede.

$\mathrm{O}$ aspecto de inserção de novos pesquisadores em redes indicou que elas têm um potencial enorme na formação de competências em áreas de investigação. Os projetos genomas do Brasil demonstraram isso ao autorizar dezenas de laboratórios a se familiarizarem com as diferentes metodologias de biologia molecular moderna.

No caso de biologia molecular estrutural espera-se o mesmo. A maioria dos laboratórios da SMOLBNet não tem nenhum domínio das metodologias envolvidas nesta área, mas seus participantes sabem que os problemas que investigam em suas linhas de pesquisa ganhariam nova luz se as estruturas de proteínas em questão fossem elucidadas. Essas linhas de pesquisa cobrem várias subáreas da biologia, como biofísica, genética, bioquímica, fisiologia, percolando por toda a biologia moderna.

O LNLS é uma instituição que tem como servir a usuários, sobretudo, pesquisadores do Brasil. Compete também ao LNLS fomentar o uso dessas facilidades. O espectrômetro de ressonância nuclear magnética está disponibilizado para os usuários, da mesma forma que as demais instalações do LNLS. As redes deverão aumentar o número de usuários qualificados, conforme treinamento na elucidação de estruturas. Esse é um processo que requer tempo. Certamente, não são esperados resultados rápidos como no caso das redes genomas. $\mathrm{O}$ seqüenciamento de DNA constitui-se em uma técnica que pode rapidamente ser absorvida por técnicos de nível médio. Apenas a anotação de genes demanda um domínio de bioinformática. Já no caso de biologia estrutural, há necessidade de capacitação em diferentes metodologias: clonagem de gene e expressão de gene em proteína; purificação de proteína; cristalização de proteína; e elucidação de estrutura mediante difração de raios $\mathrm{X}$ ou por ressonância nuclear magnética. $\mathrm{O}$ aprendizado absorve um tempo maior e demanda uma assistência contínua por parte dos pesquisadores do centro coordenador, neste caso o CBME. Na rede nacional, o Centro Nacional de Ressonância Magnética Nuclear (CNRMN) da Universidade Federal do Rio de Janeiro (UFRJ) estará cooperando na coordenação. O CBME tem em seus quadros pesquisadores que dominam todo o fluxograma de determinação de estruturas: são quatro biologistas moleculares para atender as etapas 1 e 2, três cristalógrafos, para as etapas $3 \mathrm{e}$ 4, um especialista em ressonância nuclear magnética e dicroísmo circular e outro em fluorescência de proteínas por luz UV. Conta-se ainda com um especialista em bioinformática na área de estrutural, o qual não é do quadro do LNLS, mas que estará envolvido no programa das redes.

Atualmente, o LNLS possui uma linha de luz direcionada à cristalografia de proteínas. Para que o esforço em biologia estrutural seja bem-sucedido, é fundamental que o LNLS disponha de uma linha de cristalografia com alto fluxo na região dos raios $\mathrm{X}$ duros. Isso será possível com a instalação de um dispositivo de inserção wiggler no anel e construção, na saída dele, de uma linha de luz baseada na técnica Wavelength Anomalous Dispersion (MAD). Este equipamento aumenta a capacidade de determinação de estruturas tridimensionais novas, que não apresentam homologia com outras estruturas já depositadas na base de dados de proteínas. Existem no mundo aproximadamente 100 linhas de luz MAD, todas com tempo de utilização. A instalação de uma linha de luz MAD é uma das prioridades do LNLS para os próximos anos.

\section{LNLS HOJE}

\section{Modo de Operação}

O LNLS foi criado com base em um projeto singular, tornando-se o primeiro - e, até hoje, único - laboratório síncrotron no hemisfério sul. Contando com a ousadia de uma liderança ativa e uma equipe jovem, foi possível, contra todas as dificuldades previstas, construir o maior projeto civil científico do Brasil. O sucesso desse empreendimento mostra que é possível, no Brasil, desenvolver projetos científicos de grande porte e a longo prazo. Em paralelo, criou-se um novo paradigma de "como fazer pesquisa" no país, desenvolvendo a cultura de um laboratório aberto, multi e interdisciplinar, multiusuário.

Para desenvolver sua pesquisa no LNLS, um pesquisador pode submeter individualmente seus projetos ou fazer parte de uma Rede de Pesquisa fomentada pelo LNLS. Além dos projetos das Redes, projetos individuais podem ser submetidos, os quais são enviados para assessores $a d$ hoc que emitem parecer sobre sua qualidade e viabilidade. Com base neles, periodicamente, um Comitê reúne-se para avaliar os projetos e organizar o calendário de utilização das instalações. A pesquisa pode ser realizada independentemente pelo pesquisador ou, se ele desejar, pode contar com a colaboração científica da equipe do LNLS. Ela tem a responsabilidade de manter operando as insta- 
lações, melhorá-las, conservando-as competitivas internacionalmente. Para que esta atividade seja bem-sucedida, certo tempo de uso das instalações é disponibilizado para ela.

\section{PERSPECTIVAS}

O LNLS tem como principal desafio consolidar-se como laboratório científico de classe mundial, aberto, multiusuário, multi e interdisciplinar. A mesma ousadia e determinação que permitiu a realização bem-sucedida desse empreendimento deve guiar a continuação de sua existência. A contínua implementação de novas linhas de luz, aperfeiçoamento do anel de armazenamento e ampliação dos laboratórios a esses associados deve ser mantida.

Algumas das implementações do LNLS previstas para os próximos anos são:

- Aquisição de um dispositivo de inserção wiggler e instalação de uma linha MAD, essencial para obter a estrutura tridimensional de proteínas.

- Construção de um dispositivo de inserção ondulador. Com esse dispositivo obtém-se alto fluxo na região de UV, de grande importância para pesquisas de superfície de materiais e do meio ambiente. Com a decisão de construílo no LNLS adquirir-se-á uma tecnologia nova, ampliando as capacidades técnicas da equipe além de diminuir seu custo.

- Reformas no anel de armazenamento, em particular no sistema de rádio-freqüência (RF) e no sistema de vácuo, aumentando a corrente armazenada.

- Construção de novas linhas de luz, obedecendo a demanda dos usuários. Em particular, está programado para 2002 a construção das seguintes linhas de luz: a) difração de pó, b) fluorescência no ultravioleta, para aplicações em biologia, c) uma nova linha de XAS, d) completa reconstrução da linha SAS e e) a instalação da linha de XAS-dispersivo.

- Expansão da microscopia eletrônica, com a aquisição de um microscópio de transmissão eletrônica analítico por emissão de campo de 200 kV que aumentará a capacidade de nano-análise.

- Consolidação do Grupo de Teoria para a colaboração com a pesquisa realizada no LNLS, satisfazendo uma reivindicação dos usuários. Este Grupo é responsável por desenvolver uma Rede de Teoria, a qual deve integrar-se à Rede de Teoria Internacional, procurando integrar a pesquisa experimental realizada no LNLS aos diversos grupos teóricos existentes no Brasil.
- Continuando o processo de divulgação, informação e formação, o LNLS deve intensificar seu trabalho na organização de cursos e oficinas. Um esforço deve ser feito para descentralização desses trabalhos, buscando a realização dessas atividades junto às universidades e instituições de pesquisa e aumentando a inserção do LNLS na comunidade científica e tecnológica do Brasil e da América Latina.

Um laboratório científico complexo como o LNLS deve estar permanentemente em contato com os melhores centros de pesquisa similares no mundo, ser capaz de repensar sua estratégia em função da evolução científica e tecnológica, procurando ser seu agente. Isso só pode ser feito com o dinamismo e a ousadia que sempre caracterizaram esse empreendimento. Este é o desafio a ser enfrentado nos próximos anos pela equipe do LNLS.

\section{REFERÊNCIAS BIBLIOGRÁFICAS}

BURGOS, M.B. Ciência na periferia: a luz síncrotron brasileira. Juiz de Fora, UFJF, 1999.

PIZA, D. "Sim, o Brasil tem motivos de orgulho". Folha de S.Paulo. São Paulo, 22/07/2001, p.B10-B11.

ROCO, M.C.; WILliams, R.S. e AliVisATOS, P. (eds.) Nanotechnology Research Directions: IWGN Workshop Report. International Technology Research Institute, World Technology (WTEC) Division, set. 1999.

SCIENTIFIC AMERICAN. Nova York, Scientific American, Inc. v.285, n.3, set. 2001.

SILVA, C.G. da. "The National Laboratory for Synchrotron Light: The Brazil Experience". Beamline. Stanford, Stanford Linear Accelerator Center, v.26, n.1, 1996, p.10-15.

SILVA, C.G. da; RODRIGUES, A.R. e CRAIEVICH, A.F. "The National Laboratory for Synchrotron Light of Brazil". Synchrotron Radiation News Compendium. Nova York, Gordon and Breach Science Publishers, v.1, 1988, p.52-6.

SILVA, C.G. da; RODRIGUES, A.R. e WISNIVESKY, D. "LNLS: the brazilian synchrotron light laboratory". Proceedings of the 1989 Particle Accelerator Conference. 1989, p.1.248-49.

TAVARES, P. "The Brazilian Synchrotron Light Source”. Proceedings of International Symposium on the Utilization of Accelerators, realizado em São Paulo, International Atomic Energy Agency (a ser publicado).

José Antônio Brum: Teórico de física da matéria condensada, Diretor Geral da Associação Brasileira de Tecnologia de Luz Síncrotron, Professor do Instituto de Física Gleb Wataghin - Unicamp (brum@lnls.br).

Rogério Meneghini: Bioquímico, Diretor do Centro de Biologia Molecular Estrutural do Laboratório Nacional de Luz Síncrotron (rogmeneg@lnls.br). 